\title{
Plasma rico em plaquetas associado ou não ao osso esponjoso autógeno no reparo de falhas ósseas experimentais
}

\author{
Platelet rich plasma associated or not to autogenous bone graft on the reparation of \\ experimental bone defects in the rabbits cranium \\ Paloma Sayegh Arreguy Silva ${ }^{I}$ Ricardo Junqueira Del CarloII Rogéria Serakides ${ }^{\text {III }}$ \\ Betânia Souza Monteiro' ${ }^{\mathrm{I}}$ Paula de Zorzi Balbinot ${ }^{\mathrm{I}}$ Renato Barros Eleotério $^{\mathrm{IV}}$ \\ Omar Leonardo Aristizabal Paez ${ }^{\mathrm{I}}$ Marlene Isabel Vargas Viloriav
}

\section{RESUMO}

O presente estudo avaliou a influência do plasma autógeno rico em plaquetas (PRP), associado ou não ao autoenxerto esponjoso (EOE), na reparação de falhas ósseas criadas no crânio de coelhos. A falha I foi preenchida com o PRP; a falha II com 3mg de EOE; a falha III com EOE associado ao PRP e a falha IV não foi preenchida, servindo como controle. Após as cirurgias, os animais foram separados em três grupos $e$ eutanasiados aos 30,60 e 90 dias. Na avaliação mesoscópica, independentemente do período de observação, o preenchimento ósseo, na falha controle e naquelas tratadas com PRP, iniciouse a partir das bordas para o centro e do fundo para a superfície das falhas. Já nas falhas tratadas com EOE e com enxerto associado ao PRP, foi notado também crescimento ósseo na porção central das falhas. Na análise radiográfica, foi observada maior radiopacidade no interior das falhas tratadas com EOE e com enxerto associado ao PRP, em todos os tempos. Microscopicamente, aos 30 dias, na falha tratada com EOE associado ao PRP, os fragmentos ósseos do enxerto estavam indistintos do tecido ósseo neoformado, presente em toda a borda do defeito, associado à moderada quantidade de tecido conjuntivo fibroso muito vascularizado e celularizado. Esse tecido apresentou material amorfo, eosinofílico e extracelular, junto a um processo inflamatório, constituído por linfócitos e, em menor número, por macrófagos e células gigantes multinucleadas, que podem ter influenciado negativamente a formação óssea precoce. Aos 60 e 90 dias, apenas focos ocasionais de inflamação linfocitária foram observados. O comportamento dos dois tratamentos, PRP associado ou não ao EOE, em relação a preenchimento ósseo, foi semelhante ao final do período de observação; o enxerto, utilizado de forma isolada, determinou precocidade de reparação óssea e a tromboplastina, utilizada para formação do gel de plaquetas, incitou uma reação semelhante a do tipo corpo estranho, que atuou negativamente na fase inicial de reparação.

Palavras-chave: plasma rico em plaquetas, auto-enxerto esponjoso, reparação óssea.

\section{ABSTRACT}

The present study evaluated autogenous platelet rich plasma's (PRP) influence on the reparation process of four bone defects made on rabbit's skull, associated or not to autogenous bone graft (EOE). Defect I received PRP only; defect II received $3 \mathrm{mg}$ of EOE only; defect III received EOE associated to PRP; defect IV was left to heal naturally, serving as control. After each surgery the animals were randomly divided into three groups that were euthanized at 30, 60 and 90 days. In the mesoscopic evaluation bone ingrowth started from the defect's borders to the center and from the bottom to the surface for all observation times on the control (VI) and PRP only (I) groups. In the groups treated with EOE only (II) and EOE associated to PRP (III) new bone was observed in the center of the defects. Radiographic analysis showed greater central radiopacity for groups treated with EOE only (II) and EOE associated to PRP (III) at all observation times. Microscopically in the group treated with EOE associated to PRP (III) at 30 days the graft was indistinguishable from new bone present on the border of the defect, associated to a moderate quantity of a very vascularized and cellular fibrous connective tissue. This tissue showed an extracelular eosinophilic amorphous foamy material, associated to an inflammatory process constituted by lymphocytes and in less number by macrophages and multinucleated giant cells that may have negatively influenced

'Programa de Pós-graduação em Medicina Veterinária, Departamento de Veterinária (DVT), Universidade Federal de Viçosa (UFV), Viçosa, MG, Brasil.

"Departamento de Cirurgia, DVT, UFV, Campus UFV, 36570-000, Viçosa, MG, Brasil. E-mail: ricarlo@ufv.br. Autor para correspondência.

II'Departamento de Patologia, Escola de Veterinária, UFMG, Belo Horizonte, MG, Brasil.

${ }^{\mathrm{IV}}$ Curso de Medicina Veterinária, DVT, UFV, Viçosa, MG, Brasil.

${ }^{\vee}$ Departamento de Patologia, DVT, UFV, Viçosa, MG, Brasil. 
early bone formation. At 60 and 90 days occasional spots of lymphocytic inflammation were observed. Both treatments, PRP associated or not to EOE, were similar for the bone ingrowth at the final time of observation; the graft used alone determined early bone reparation and thromboplastine used for the platelet gel formation incited a foreign body-like reaction that acted negatively on the initial reparation.

Key words: platelet rich plasma, autogenous bone graft, bone reparation.

\section{INTRODUÇÃO}

O tecido ósseo exibe grande potencial regenerativo, sendo capaz de reparar fraturas e defeitos locais com semelhança estrutural, desde que estejam presentes células osteocompetentes, mediadores biológicos, matriz, vascularização e suporte sanguíneo eficiente (CANDINI, 2001).

Os fatores de crescimento (FGs) são proteínas solúveis que agem nas células osteoprogenitoras diferenciando-as e estimulando a atuação dessas células. Desde a década de 80 , tem-se investigado a possibilidade utilizar FGs na modulação da reparação óssea (ROLDAN et al., 2004)

As plaquetas chegam rapidamente no local da ferida e liberam múltiplos FGs e citocinas, incluindo: fator de crescimento transformador $\beta$ (TGF/ $\beta 1$ e $\beta 2$ ), fator de crescimento vascular endotelial (VEGF), fator de crescimento celular endotelial derivado das plaquetas (PDEGF), interleucina-1 (IL-1), e fator ativador de plaquetas-4 (PAF-4). O plasma rico em plaquetas (PRP) é uma fonte autógena de fatores de crescimento (LIEBERMAN et al., 2002), que favorecem a reparação óssea e a vascularização local, característica vital para integração de enxertos ósseos (AGHALOO et al., 2002).

O presente estudo teve por objetivo avaliar a influência do PRP, associado ou não ao enxerto esponjoso autógeno, na reparação de falhas ósseas criadas no crânio de coelhos, por meio de exames mesoscópicos, radiográficos e microscópicos, justificando-se como uma alternativa ao arsenal terapêutico ortopédico veterinário.

\section{MATERIAL E MÉTODOS}

Foram utilizadas 18 coelhas da raça Nova Zelândia, com peso médio de $3,5 \mathrm{~kg}$ e 9 meses de idade. No pré-operatório, por meio da punção do plexo venoso retro orbital, foram obtidos $9 \mathrm{~mL}$ de sangue de cada animal. $\mathrm{O}$ sangue coletado foi armazenado em dois tubos vacutainer (de $4,5 \mathrm{~mL}$ ), contendo citrato de sódio. O conteúdo dos tubos foi homogeneizado e centrifugado ${ }^{a}$ a 1300rpm por 12 minutos. Após a centrifugação, numa capela de fluxo laminar, o plasma foi separado das hemácias, passando a existir entre eles uma camada intermediária, denominada zona de névoa, constituída de leucócitos, plaquetas e hemácias maiores. Foram pipetados $25 \mu \mathrm{L}$ da zona de névoa por tubo e reservados em um tubo devidamente identificado. Uma nova centrifugação do plasma foi realizada, a 1300rpm, por oito minutos. Nos tubos retirados da centrífuga, foi observado o botão de plaquetas, que permaneceu no fundo de cada tubo, bem como o plasma, que ficou separado, ocupando o restante do tubo. Foi retirado o plasma sobrenadante, permanecendo apenas $125 \mu \mathrm{L}$ formados pelo plasma e pelo botão plaquetário. Ao agitar o tubo, ocorreu a ressuspensão do botão e a coloração original do PRP. Foram adicionados $25 \mu \mathrm{L}$ da zona de névoa, obtendo-se o PRP final, que foi checado quanto ao número de plaquetas ao microscópio óptico. O PRP deve ser superior a 1 milhão de plaquetas em $1 \mu \mathrm{L}$ para ser considerado positivo. Posteriormente, foram separados, em um frasco, $75 \mu \mathrm{L}$ de soluplastin , seguindo a proporção 2:1 (150 $\mathrm{L}$ de PRP para $75 \mu \mathrm{L}$ de coagulante). No momento da cirurgia, o soluplastin ${ }^{\circledR}$ foi adicionado ao PRP para confecção do gel de plaquetas.

Previamente ao procedimento cirúrgico, todos os animais foram pré-anestesiados com acepromazina $^{c} \mathrm{e}$, em seguida, submetidos à anestesia geral com quetamina ${ }^{\mathrm{d}}$ e xilazina ${ }^{\mathrm{e}}$. Também foi aplicada anestesia epidural com $0,9 \mathrm{ml}$ de lidocaína ${ }^{\mathrm{f}}$ a $2 \%$. A antibioticoterapia foi realizada com enrofloxacina ${ }^{\mathrm{g}}$, após a indução anestésica e nos seis dias subseqüentes ao procedimento cirúrgico. A analgesia foi obtida com morfina ${ }^{\mathrm{h}}$ no período pré-operatório e a cada oito horas após a cirurgia, durante três dias.

Após a exposição do osso parietal (PIERMATTEI, 1993), com auxílio de uma trefina cirúrgica ${ }^{i}$ de $5,0 \mathrm{~mm}$ de diâmetro, foram realizadas quatro falhas ósseas na região fronto-parietal, sendo duas no antímero direito e duas no esquerdo, atingindo ambas as corticais, com exposição das meninges no fundo. Essas falhas, afastadas entre si por $3 \mathrm{~mm}$, foram numeradas de I a IV. A falha I foi preenchida com o PRP; a falha II foi completamente preenchida com enxerto esponjoso autógeno; a falha III com enxerto esponjoso autógeno associado ao PRP e a falha IV não foi preenchida, servindo como controle.

Após a realização das quatro falhas, $6 \mathrm{mg}$ de osso esponjoso autógeno foram coletados da crista ilíaca direita, pesados e, posteriormente, depositados $3 \mathrm{mg}$ na falha II e $3 \mathrm{mg}$ na falha III. Ao término dos procedimentos cirúrgicos, as fáscias, os músculos e a pele foram suturados de maneira convencional. Os 
animais foram separados aleatoriamente em três grupos experimentais (G1, G2 e G3), constituídos de seis coelhas e eutanasiados aos 30,60 e 90 dias, respectivamente, por grupo, com sobredosagem anestésica.

Ao exame mesoscópico, post-mortem, foram observadas as características dos tecidos presentes na falha, com auxílio de uma lupa, com aumento de até 50 vezes. Os sítios cirúrgicos foram radiografados, após a eutanásia, afim de avaliar o grau de preenchimento ósseo das falhas, determinado pela radiopacidade na área da falha, segundo os seguintes escores préestabelecidos: falhas com preenchimento ósseo entre 0 $<\mathrm{x} \leq 25 \%$ : escore 1 ; preenchimento ósseo entre $26<\mathrm{x} \leq$ $75 \%$ : escore 2 e, preenchimento ósseo ( $75 \%$ : escore 3 .

Para avaliação microscópica, fragmentos ósseos, da região de cada falha, foram processados de acordo com técnicas histológicas rotineiras, corados com hematoxilina e eosina (HE) e examinados ao microscópio óptico e classificados segundo escores pré-estabelecidos para a intensidade de preenchimento ósseo: $0<\mathrm{x} \leq 25 \%, 1 ; 26<\mathrm{x} \leq 75 \%, 2$ e $(75 \%, 3$.

Após a organização das variáveis envolvidas, os resultados foram submetidos ao modelo de Kruskall-Wallis, a 5\% de significância, pelo programa BioEstat 2.0 (AYRES et al., 2000).

\section{RESULTADOS E DISCUSSÃO}

$\mathrm{Na}$ avaliação mesoscópica, independentemente do período de observação, o preenchimento ósseo na falha controle e naquelas tratadas com PRP isoladamente iniciou-se a partir das bordas para o centro e do fundo para superfície das falhas. Em alguns animais, da mesma forma que observado por MONTEIRO et al. (2007), o tecido de preenchimento apresentou aspecto menos compacto que o tecido vizinho que, provavelmente, está relacionado à imaturidade do tecido ósseo formado. Já nas falhas tratadas com enxerto e com enxerto associado ao PRP, foi notado crescimento ósseo na porção central das falhas, diferentemente do preenchimento centrípeto dos grupos anteriores. Esse achado pode estar relacionado à presença do enxerto depositado no centro da falha, que promoveu osteogênese precoce e estimulou a formação óssea direta, conforme descreveram ALLEGRINI et al. (2004).

$\mathrm{Na}$ análise radiográfica (Figura 1), foi observada maior radiopacidade no interior das falhas tratados com enxerto e naquelas tratadas com enxerto associado ao PRP, em todos os tempos. Aos 30 dias, foi notado que, nas falhas controle e nas tratadas com PRP, a reparação se processou a partir das bordas. No dia 60 , em todas as falhas, foi possível visualizar que a radiopacidade foi menor quando comparada ao osso receptor. Já aos 90 dias, todas as falhas tratadas com enxerto e enxerto associado ao PRP manifestaram opacidade semelhante à do osso receptor.

Com relação à análise estatística do grau de preenchimento ósseo das falhas, os tratamentos com enxerto e enxerto associado a PRP, quando comparados à falha controle, apresentaram maiores postos médios e, conseqüentemente, melhor reparação óssea. Quando comparadas a falha tratada com PRP e aquelas tratadas com enxerto e enxerto associado ao PRP, foram observadas diferenças significativas. No entanto, isso não aconteceu entre a falha controle e a tratada com PRP isoladamente, concordando com AGHALOO et al. (2002), os quais afirmaram que os fatores de crescimento, inerentes ao PRP, necessitam de substrato para manifestação de ação e, nesse caso, o enxerto ósseo usado como carreador não estava presente.

Além disso, a ausência de diferença estatística entre a falha controle e a tratada com PRP isoladamente sugere que os efeitos dos FGs presentes não se manifestaram nos diversos períodos de observação. Isso pode ser explicado pelos relatos de ROLDÁN et al. (2004), os quais afirmaram que o PRP isoladamente não forma osso novo por estimulação e diferenciação de células mesenquimais. No entanto, a presença de FGs no PRP confere-lhe capacidade osteoindutora, que é dependente da presença de células presentes no enxerto para se manifestar.

$\mathrm{Na}$ análise microscópica (Figura 2), aos 30 dias, o defeito ósseo da falha controle apresentou cerca de $20 \%$ da área ocupada por neoformação óssea discreta, presente em alguns pontos da borda da lesão, e associada à moderada quantidade de tecido conjuntivo fibroso vascularizado. $\mathrm{O}$ osso neoformado cresceu das bordas do defeito em direção ao centro e foi do tipo trabecular e imaturo (osteóide), contendo osteócitos de tamanhos variados e revestidos por uma camada de osteoblastos na maioria achatados ou cuboidais. Aos 60 dias, o defeito ósseo apresentou-se menor em comparação aos 30 dias e preenchido por tecido ósseo neoformado e tecido conjuntivo fibroso vascularizado. As bordas do defeito, às vezes, estavam indistintas do tecido ósseo neoformado. Aos 90 dias, o defeito apresentou-se preenchido por tecido ósseo e conjuntivo, à semelhança dos 60 dias. Observou-se, no conjuntivo fibroso, intensa celularidade, com fibroblastos e osteoblastos. Houve áreas de condensação do colágeno sobre as quais foi produzido tecido ósseo imaturo (formação óssea intramembranosa). Entretanto, até os 90 dias, não houve em nenhum dos animais preenchimento total do defeito, restando cerca de 40$50 \%$ de área a ser preenchida. 


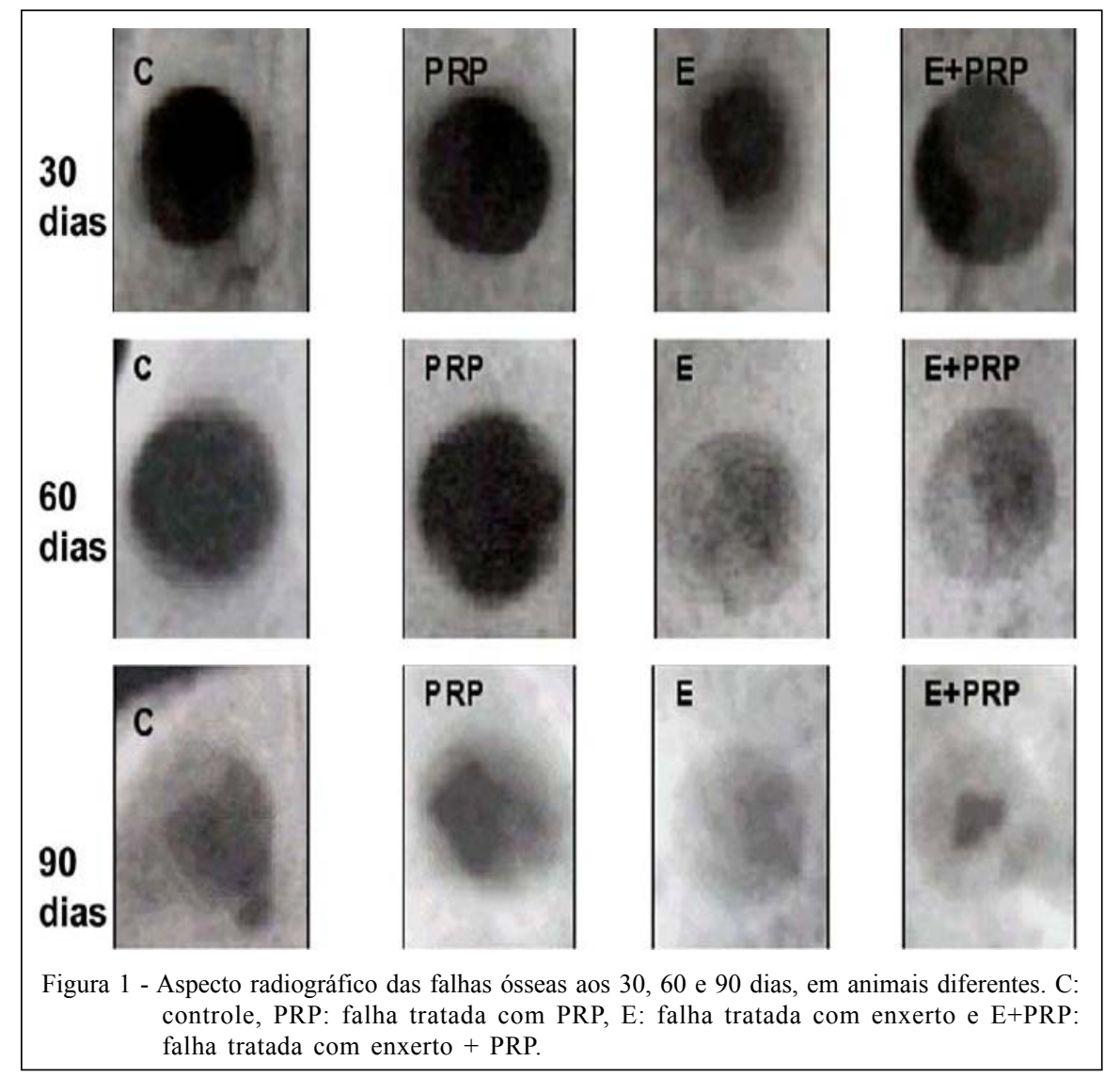

Para todos os tempos avaliados, a morfologia e a extensão do preenchimento do defeito ósseo evidenciada na falha tratada com PRP foi semelhante à observada na falha controle, em todos os períodos estudados. No entanto, junto ao tecido ósseo neoformado houve tecido conjuntivo fibroso mais proeminente. No tecido conjuntivo, observou-se, principalmente aos 30 e 60 dias, um material eosinofílico, espumoso, amorfo, extracelular, associado a processo inflamatório multifocal, discreto a moderado. CANDINI (2001) também relata ter encontrado processo inflamatório sem, contudo, detalhar a presença de linfócitos, macrófagos e células gigantes multinucleadas como encontrado no presente estudo. Já aos 90 dias, o processo inflamatório não foi mais evidenciado, provavelmente, pela absorção do gel nesse período, porém, não houve diferença em comparação ao grupo controle no que concerne ao preenchimento ósseo.

O soluplastin ${ }^{\circledR}$ contém, em sua composição, além de cloreto de cálcio e cloreto de sódio, tromboplastina derivada do cérebro de coelho, que pode ter incitado uma reação semelhante à reação do tipo corpo estranho. Isso pode ter influenciado negativamente a resposta da associação do PRP ao enxerto, cuja principal diferença esperada, em relação ao enxerto usado de forma isolada, deveria ser a formação óssea mais precoce, que não foi observada.

Aos 30 dias, a falha tratada com enxerto esponjoso autógeno apresentou a área do defeito totalmente preenchida por fragmentos do implante, tecido ósseo neoformado e grande quantidade de tecido conjuntivo fibroso. O implante apresentou-se viável, caracterizado pela presença de osteoblastos e osteócitos ativos. Ele estava bem individualizado do tecido ósseo neoformado, que foi mais maduro em comparação à falha controle, nesse mesmo período. Aos 60 dias, a falha apresentou-se maior e preenchida por menor quantidade de tecido conjuntivo fibroso, com implantes ósseos ausentes ou presentes em menores proporções, em comparação aos 30 dias. Aos 90 dias, o tamanho da falha era semelhante a do grupo controle, bem como a quantidade de tecido conjuntivo. Esses fatos podem ser explicados por LEMOS et al. (2002), os quais observaram, durante as quatro semanas iniciais, que a fase celular e bioquímica da regeneração óssea é intensa e, com o tempo, o osso sofre reabsorção e remodelação, ocorrendo uma fase menos celular, mais mineralizada e estruturalmente mais organizada.

Ciência Rural, v.39, n.1, jan-fev, 2009. 


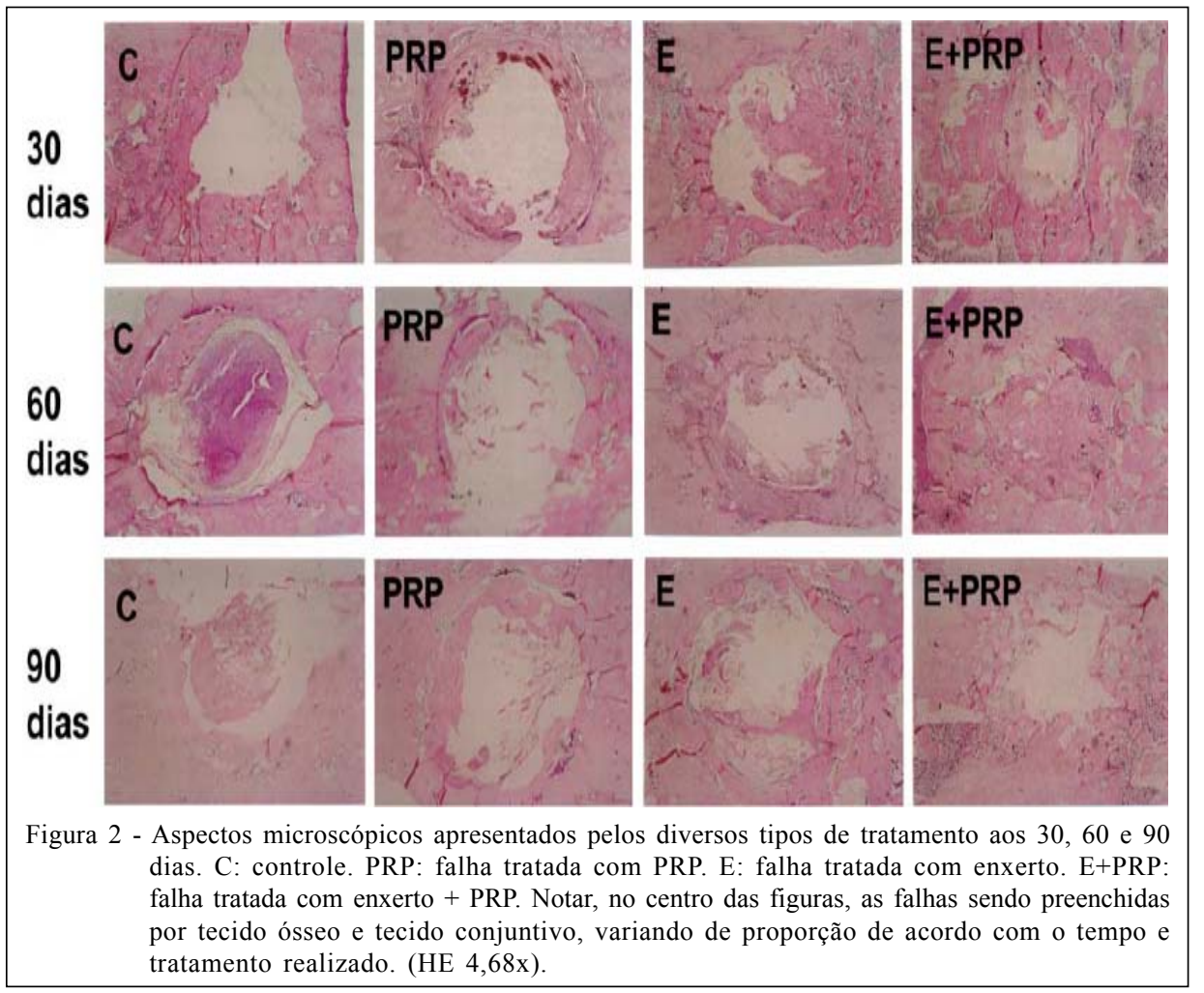

Aos 30 dias, na falha tratada com enxerto esponjoso autógeno associado ao PRP, o defeito ósseo apresentou-se mais preenchido em comparação ao controle. Os fragmentos ósseos do enxerto estavam presentes em toda a borda do defeito, associados à moderada quantidade de tecido conjuntivo fibroso muito vascularizado e celularizado. $\mathrm{O}$ tecido ósseo neoformado foi do tipo trabecular, mais maduro em comparação ao controle e com focos osteônicos. Houve ainda alguns focos de osso imaturo (osteóide). As trabéculas apresentavam osteócitos, ora ativos, ora inativos, e estavam revestidas por uma ou mais camadas de osteoblastos aumentados de volume. O tecido conjuntivo fibroso que ocupava algumas áreas do defeito apresentou material amorfo, espumoso, eosinofílico (semelhante ao gel formado pelo soluplastin ${ }^{\circledR}$ ) e extracelular, junto a processo inflamatório, constituído predominantemente por linfócitos e, em menor número, por macrófagos e células gigantes multinucleadas que apresentavam citoplasma espumoso. Houve também áreas de condensação do colágeno sobre as quais havia síntese de novo osso. Aos 60 e 90 dias, a hiperplasia e a hipertrofia osteoblástica eram menos expressivas, mas a área do defeito estava mais preenchida, quando comparada ao período anterior e aos demais grupos estudados.
$\mathrm{Na}$ análise estatística dos resultados, com relação à análise microscópica das falhas, o PRP associado ao enxerto apresentou melhores resultados nos diferentes tempos de observação. Segundo MARX, (2001), isso se deve às células presentes no enxerto que possuem receptores para os FGs do PRP, produzindo, assim, melhor resultado em comparação com os tratamentos isolados.

Entretanto, quando são comparados enxerto e enxerto+PRP, ao longo do tempo, pode-se deduzir que o grupo enxerto regrediu (escore 2), enquanto o preenchimento desencadeado pela associação enxerto+PRP evoluiu (escore 3). Provavelmente, o que ocorreu foi que, aos 60 e 90 dias, as falhas tratadas com enxerto já se encontravam em fase de remodelação e deposição mineral, portanto, menos celular, conforme descrito por LEMOS et al. (2002). Entre PRP e controle não foram constatadas diferenças significativas, nem entre o enxerto e o enxerto associado ao PRP.

\section{CONCLUSÃO}

Após a utilização do PRP associado ou não ao enxerto esponjoso autógeno, pode-se concluir que: 1) ao final do período de observação, o comportamento dos dois tratamentos (PRP e PRP+EOE), em relação a 
preenchimento ósseo, é semelhante; 2) o enxerto, utilizado de forma isolada, determina precocidade de reparação óssea; 3) o soluplastin ${ }^{\circledR}$, utilizado para formação do gel de plaquetas, pode ter incitado uma reação semelhante à do tipo corpo estranho, que atua negativamente na fase inicial da reparação.

\section{COMITÊ DE ÉTICA E BIOSSEGURANÇA}

O projeto foi aprovado pelo comitê de ética na pesquisa com animais do Departamento de Veterinária, da Universidade Federal de Viçosa (UFV). Protocolo: 21/2006.

\section{FONTES DE AQUISIÇÃO}

${ }^{a}$ Centrífuga ${ }^{\circledR}$ FANEN. São Paulo, SP, Brasil.

b Soluplastin ${ }^{\circledR}$ WienerLaboratórios S.A.I.C. Rosário, Argentina

${ }^{c}$ Acepram ${ }^{\circledR}$ 1\% - Univet. SP, Brasil.

${ }^{\text {d }}$ Quetamina. Cristália Produtos Químicos e Farmacêuticos Ltda

e Xilazina. Rompum, Bayer S.A., São Paulo, Brasil

${ }^{f}$ Lidocaína ${ }^{\circledR} 2 \%$ - Anestésico Bravet. SP, Brasil

${ }^{g}$ Enropet $^{\circledR} 25 \mathrm{mg} / \mathrm{ml}$-Vetbrands. SP, Brasil

${ }^{\text {h }}$ Dimorf $^{\text {B }}$ Solução Oral - Cristália Ltda. SP, Brasil.

${ }^{\mathrm{i}}$ Microretífica Dremel - Bosch, RJ, Brasil

\section{REFERÊNCIAS}

AGHALOO, T.I. et al. Investigation of platelet-rich plasma in rabbit cranial defects: a pilot study. Journal Oral Maxillofacial Surgery, v.60, n.10, p.1176-1181, 2002.

ALLEGRINI, S.J. et al. Bone regeneration in rabbit sinus lifting associated with bovine BMP. Journal Biomedical Materials Research, v.15, n.68B(2), p.127-131, 2004.
AYRES, M.M. et al. Bioestat 2.0. Aplicações estatísticas nas áreas das ciências biológicas e médicas. Belém/ Brasília: Sociedade Civil Mamirauã/CPPq, 2000. 272p.

CANDINI A.L. Avaliação do efeito do plasma rico em Plaquetas foto-estimulado pelo laser de baixa potência no processo de regeneração óssea. 2001. 108f. Dissertação (Mestrado em Odontologia) - Universidade do Vale do Paraíba, São José dos Campos.

LEMOS, J.J. et al. Utilização de plasma rico em plaquetas em enxertos ósseos- proposta de um protocolo de obtenção simplificado. Internet Health Company do Brasil S/A. Medcenter Periodontia. Capturado em 12/01/2002. Online. Disponível em: www.odontologia.com.br/artigos.asp?id=225.

LIEBERMAN, J.R. et al. The hole of growth factors in repair bone. Journal of Bone and Joint Surgery, v.84(A), n.6, p.1032-1042, 2002.

MARX, R.E. Platelet-rich plasma (PRP): what is PRP and what is not PRP? Implant Dentistry, n.4, v.10, p.225-228, 2001 .

MONTEIRO, B.S. et al. Proteínas morfogenéticas ósseas (BMPs) associadas a osso esponjoso autógeno na reparação de falhas experimentais na calota craniana de coelhos. Arquivo Brasileiro de Medicina Veterinária e Zootecnia, v.59, p.745-751, 2007.

PIERMATTEI, D.L . In: - An atlas of surgical approaches to the bones and joints of the dog and cat. 3ed. Philadelphia: Saunders, 1993. p.40-41.

ROLDÁN, J.C. et al. Bone formation in the presence os plateletrich plasma vs. bone morphogenetic protein-7. Bone, v.34, n.1, p.80-90, 2004. 